\title{
Effect of pranayama on anxiety and pain among patients undergoing cardiac surgery: A non-randomized controlled trial
}

\author{
Ramesh Chandrababu ${ }^{\mathrm{a}, *}$, Sreelekha Bhaskara Kurup ${ }^{\mathrm{b}}$, N. Ravishankar ${ }^{\mathrm{c}}$, Jyothi Ramesh ${ }^{\mathrm{d}}$ \\ ${ }^{a}$ Manipal College of Nursing, Manipal Academy of Higher Education, Manipal, Karnataka, 576104, India \\ ${ }^{\mathrm{b}}$ Sri Ramachandra College of Nursing, Sri Ramachandra Institute of Higher Education and Research, Porur, Chennai, 600116, India \\ ${ }^{c}$ Department of Statistics, Prasanna School of Public Health, Manipal Academy of Higher Education, Manipal, Karnataka, 576104, India \\ ${ }^{\mathrm{d}}$ Udupi College of Nursing, Shree Krishna Educational Trust, Manipal, Karnataka, 576104, India
}

\section{A R T I C L E I N F O}

\section{Keywords:}

Cardiac surgical procedures

Anxiety

Pain

Postoperative care

Yoga

\begin{abstract}
A B S T R A C T
Background: Major cardiac surgery could be physically and mentally stressful. Anxiety and pain are commonly experienced by patients while undergoing cardiac surgery. Yoga is recognized as the most beneficial complementary and alternative therapy.

Objective: To assess the effect of alternate nostril breathing exercises (pranayama) on anxiety and pain among patients undergoing cardiac surgery.

Methods: A non-randomized controlled trial was adopted as study design and involved 48 patients undergoing cardiac surgery. The experimental group $(n=24)$ received pranayama study intervention while the control group $(n=24)$ received routine care of the hospital. Outcomes were state anxiety and pain, measured with the state anxiety inventory and a visual analogue scale respectively. Data were analyzed by SPSS version 20.0. Repeated measures ANOVA was used to test the effect of the intervention.

Results: Study results showed that patients in the experimental group experienced a significant decrease in anxiety $(\mathrm{p}<0.05)$ than the control group. There was a decrease in pain scores but was not statistically significant across different time point measurements at $\mathrm{p}<0.05$ between the groups.

Conclusion: These findings support the use of pranayama for decreasing anxiety among patients undergoing cardiac surgery. However, there is a need for randomized controlled trials with higher sample size to confirm this results. Future trials also should focus on the estimation of relevant biomarkers such as endorphins to understand the scientific rationale.
\end{abstract}

\section{Introduction}

Cardiovascular diseases (CVD) has become the leading health issue in both the developing and the developed countries. ${ }^{1}$ Nearly 32 million Indians suffer from some form of heart disease, according to extrapolations from the Global Burden of Diseases study. Undergoing major heart surgery could be physically and mentally stressful. ${ }^{2}$ Anxiety and pain are commonly experienced by patients while undergoing cardiac surgery. These symptoms can result in prolonged recovery after the surgery. ${ }^{3}$ Postoperative outcomes such as anxiety, depression, and pain are common issues during cardiac surgery and closely related to the recovery of patients. ${ }^{4}$

Yoga is recognized as a most beneficial complementary and alternative therapy. Yoga is being explored currently in the western countries due to its increased reputation among the broader population. Yoga incorporates the body and mind for positive health benefits; it comprises of Asanas (Yogic exercise) Pranayama (yogic breathing exercises) and Dhyana (Meditation). ${ }^{5}$ Research studies have reported that the practice of yoga (pranayama and asana) improves symptoms of atrial fibrillation, anxiety, depression, and quality of life. ${ }^{6}$ Pranayama enhance cardiorespiratory system, ${ }^{7}$ pulmonary functions ${ }^{8,9}$ blood pressure, heart rate, ${ }^{10}$ lipid profile, left ventricular ejection fraction (LVEF), and psychological states. $^{11}$

A systematic review and meta-analysis of randomized controlled trials reported that yoga is a promising intervention in improving cardio-metabolic health. ${ }^{12}$ Yoga appears to be beneficial in improving

\footnotetext{
* Corresponding author.

E-mail addresses: ramesh.c@manipal.edu (R. Chandrababu), sreelekha.b@sriramachandra.edu.in (S.B. Kurup), ravi.shankar@manipal.edu (N. Ravishankar), joeram06@yahoo.com (J. Ramesh).
} 
biological modifiable risk factors for cardiovascular diseases. Yoga can play an essential role in the prevention of cardiovascular diseases. ${ }^{13}$ Yoga-based rehabilitation program improved physical, mental health and quality of life after coronary artery bypass graft surgery. ${ }^{14}$ Modified yoga program after heart surgery significantly decreased stress, anxiety and pain. ${ }^{15}$

Healthcare professionals play an essential role and face challenges to overcome postoperative outcomes such as pain, anxiety, and stress in caring for patients undergoing cardiac surgery. There is a need for healthcare professionals to implement an effective non-pharmacologic intervention to decrease anxiety, and pain. Therefore, the present study aimed to evaluate the effect of alternative breathing exercise in reducing anxiety and pain among patients undergoing cardiac surgery.

\section{Aim}

The aim of this study is to evaluate the effect of alternate nostril breathing exercises (pranayama) on anxiety and pain among patients undergoing cardiac surgery.

\section{Methodology}

\subsection{Design and setting}

A non-randomized controlled trial was adopted as a research design. This study was conducted inwards of cardiovascular and thoracic surgery of a tertiary care hospital. This study conformed the Declaration of Helsinki ${ }^{16}$ and was approved by the institutional research ethics committee. Informed consent obtained from the study participants and they had the freedom to withdraw from the study at any point in time.

\subsection{Sample}

The research sample of this study were adult patients who undergo any form of heart surgery includes coronary artery bypass graft surgery (CABG), valve replacement or repair. The sample size calculated considering anxiety as the primary outcome according to a previous study ${ }^{18}$ and estimated sample size in each group was 24 this would achieve the power of $80 \%$ at a level of significance of 0.05 . A total of 48 patients were recruited using non-probability purposive sampling technique and assigned 24 patients in the experimental group and 24 in the control group. Patients who undergo first-time cardiac surgery, aged between 21 and 70 in years, both the gender and who can follow the instructions were the inclusion criteria. The exclusion criteria applied were; patients who were taken for redo surgery and not weaned off from the mechanical ventilator within $48 \mathrm{~h}$ after surgery were the exclusion criteria.

\subsection{Study instruments}

Three instruments were used to collect the data from the study patients: Socio-demographic characteristics and clinical variables, state anxiety inventory and visual analogue scale. Demographic and clinical variables included age, sex, religion, education, family history of heart disease, a habit of smoking, regular exercise, diabetes mellitus, hypertension, and type of heart surgery. Content validity done with the panel of experts and the items were modified based on their suggestions. Calculated content validity index (CVI) of the tool was 0.93 .

The visual analogue scale was utilized to assess the pain, this is a standardized scale, and it is considered to be the most appropriate tool for evaluating pain intensity among patients undergoing major surgeries. Reliability of the instrument is 0.93 found to be good to evaluate the pain intensity. ${ }^{17}$ State anxiety inventory was used to measure the anxiety and is comprised of 20 items. The tool has the range of score between 20 and 80, with the higher scores demonstrating higher anxiety levels. Reliability of the state anxiety inventory is 0.90 .

\subsection{Intervention}

Two days before the surgery pranayama technique was taught and demonstrated to patients. An informational leaflet given on steps of pranayama and patients were made to perform a return demonstration to ensure that patients are doing it correctly. The duration of pranayama technique was $15 \mathrm{~min}$. Pranayama intervention was provided for three consecutive post-operative days from day three to five after the cardiac surgery. Intervention and assessment were carried out before $30 \mathrm{~min}$ of medication administration to minimize drug effects on study outcomes.

\subsection{Data collection}

After assessing the eligibility criteria, patients were recruited in the study and complete details about the study was explained to them. To decrease the risk of diffusion of intervention patients were recruited to the experimental and control groups on separate wards. All patients in the experimental group received intervention while the control group did not. Two days before the surgery state anxiety inventory was administered to assess preoperative anxiety. On third postoperative day morning, the state anxiety was measured. Patients in the experimental group performed alternative nostril breathing exercises (Pranayama) for $15 \mathrm{~min}$, and the investigator guided it. The investigator had a checklist to assess the fidelity of intervention and made sure that patients were adhering to study interventions.

The same intervention provided on the fourth and fifth postoperative day. Before and after of each session of intervention, pre and post-intervention of pain scores assessed and on the fifth postoperative day after intervention state anxiety were measured. The control group did not receive any intervention and received usual postoperative care of the hospital. A calm environment provided to patients during all the sessions of intervention to avoid distractions. The process of data collection presented in Fig. 1.

\subsection{Statistical analysis}

The collected data were analyzed using the Statistical Package for Social Sciences (SPSS version 20). The descriptive and inferential statistics utilized. The frequency, percentage, mean and standard deviation were calculated to describe the patient's demographics \& clinical variables and level of pain and anxiety. Chi-square test used to assess the homogeneity among patients in both groups. Effect of pranayama on anxiety and pain evaluated by using repeated measures ANOVA.

\section{Results}

A total of 48 patients were enrolled: 24 allocated in the experimental and 24 in the control group. The majority of the study patients were male $35(72 \%)$. Mean age of patients were 58.72 with a standard deviation of 9.10. Most of them were belongs to Hindu religion. The majority of the patients had history hypertension, diabetes mellitus, and habit of smoking. Most of them did not have the habit of regular exercise and underwent CABG surgery. Demographic and clinical characteristics of patients are presented in Table 1. At baseline, there were no significant differences between the two group in the characteristics of patients and the outcome measures.

Mean score of preoperative anxiety scores in the experimental group and the control group were $55.08 \pm 4.45$ and $55.54 \pm 6.71$ 


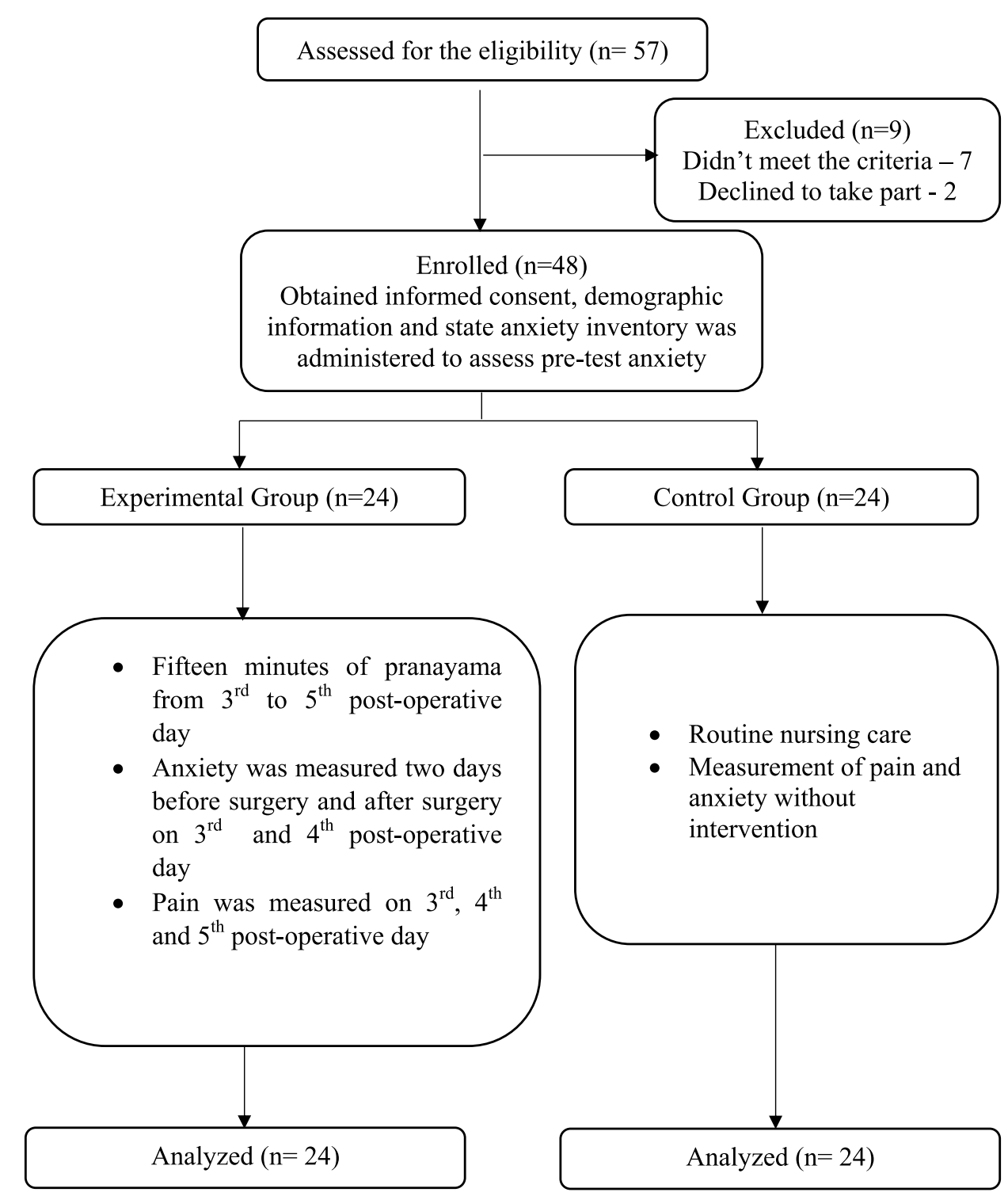

Fig. 1. Process of data collection.

respectively (Table 2). There was a gradual and higher decrease in anxiety scores during post-intervention assessment in the experimental group than the control group. Repeated measures ANOVA on the effect of pranayama on anxiety scores revealed that there was a significant statistical difference between groups at $\mathrm{p}<0.05$ (Table 3 ).

Regarding the effect of pranayama on pain repeated measures ANOVA demonstrated that there was a significant difference on the 3rd postoperative day $(\mathrm{p}<0.05)$. However, further analysis of pain scores applying repeated measures revealed no significant statistical difference between groups at $\mathrm{p}<0.05$ on the fourth and fifth postoperative day (Table 4).

\section{Discussion}

The study results indicated significant effects of pranayama among patients who received the interventions than who did not. Our findings exposed that patients in both groups (experimental and control) had a high level of anxiety during the preoperative period and on the 3rd postoperative day before the intervention. It could be because major heart surgery is a stressful event that results in substantial anxiety because patients may think about complications in the postoperative period and concern regarding their recovery. There was a more significant decrease in anxiety among patients in the experimental group. Hence, the pranayama intervention significantly benefits the patients on undergoing cardiac surgery.

The present study findings confirm the results of the previous study on the effect of yoga intervention on anxiety after CABG surgery. ${ }^{18}$ Earlier research studies on pranayama described that pranayama significantly indices of ventricular repolarization dispersion in patients with arrhythmia, ${ }^{19}$ regular practice of yoga decreases stress and anxiety and improves cognition and quality of life. ${ }^{20} \mathrm{~A}$ systematic review of yoga supported that consistent practice of yoga results in reduced cholesterol level and has a more significant decrease in blood pressure of hypertensive patients. ${ }^{21}$

\subsection{Strength and limitations of this study}

This study evaluated the effect of pranayama among patients 
Table 1

Demographic and clinical characteristics of the participants.

\begin{tabular}{|c|c|c|c|c|c|c|}
\hline \multirow[t]{2}{*}{ Demographic and clinical characteristics } & \multicolumn{2}{|c|}{ Experimental Group $(n=24)$} & \multicolumn{2}{|c|}{ Control Group $(\mathrm{n}=24)$} & \multirow[t]{2}{*}{$\chi^{2}$} & \multirow[t]{2}{*}{$\mathrm{p}$} \\
\hline & Frequency & Percentage & Frequency & Percentage & & \\
\hline \multicolumn{7}{|l|}{ Gender } \\
\hline Male & 18 & 75.0 & 17 & 70.8 & 0.497 & 0.48 \\
\hline Female & 6 & 25.0 & 7 & 29.1 & & \\
\hline \multicolumn{7}{|l|}{ Education } \\
\hline Non-formal & 4 & 16.6 & 4 & 16.6 & & 0.23 \\
\hline Primary & 3 & 12.5 & 4 & 16.6 & 4.29 & \\
\hline Higher Secondary & 7 & 29.1 & 7 & 29.1 & & \\
\hline Graduate & 10 & 41.6 & 9 & 37.5 & & \\
\hline \multicolumn{7}{|l|}{ Religion } \\
\hline Hindu & 13 & 54.1 & 12 & 50.0 & & 0.17 \\
\hline Christian & 7 & 29.1 & 5 & 20.8 & 3.43 & \\
\hline Muslim & 4 & 16.6 & 3 & 12.5 & & \\
\hline \multicolumn{7}{|l|}{ Family history } \\
\hline Yes & 16 & 66.6 & 17 & 70.8 & 1.30 & 0.25 \\
\hline No & 8 & 34.3 & 7 & 29.1 & & \\
\hline \multicolumn{7}{|l|}{ Regular exercise } \\
\hline Yes & 7 & 29.1 & 8 & 34.3 & 0.21 & 0.64 \\
\hline No & 17 & 70.8 & 16 & 66.6 & & \\
\hline \multicolumn{7}{|l|}{ Smoking } \\
\hline Yes & 10 & 41.6 & 9 & 37.5 & 1.80 & 0.17 \\
\hline No & 14 & 58.3 & 15 & 62.5 & & \\
\hline \multicolumn{7}{|l|}{ Hypertension } \\
\hline Yes & 18 & 75.0 & 19 & 79.1 & 1.1 & 0.20 \\
\hline No & 6 & 25.0 & 5 & 20.8 & & \\
\hline \multicolumn{7}{|l|}{ Diabetes mellitus } \\
\hline Yes & 19 & 79.1 & 18 & 75 & 0.70 & 0.40 \\
\hline No & 5 & 20.8 & 6 & 25 & & \\
\hline \multicolumn{7}{|l|}{ Type of heart surgery } \\
\hline CABG & 16 & 66.6 & 15 & 62.5 & & 0.40 \\
\hline Valve repair & 4 & 16.6 & 4 & 16.6 & 1.823 & \\
\hline Valve replacement & 4 & 16.6 & 5 & 20.8 & & \\
\hline
\end{tabular}

Table 2

Mean scores of anxiety in the experimental and the control group.

\begin{tabular}{lllll}
\hline Outcome measures & \multicolumn{2}{l}{ Experimental $(\mathrm{n}=24)$} & \multicolumn{2}{l}{ Control $(\mathrm{n}=24)$} \\
\cline { 2 - 5 } & Mean & SD & Mean & SD \\
\hline Before surgery & 55.08 & 4.45 & 55.54 & 6.71 \\
Pre-intervention & 49.20 & 5.67 & 53.58 & 3.09 \\
Post-intervention & 39.25 & 3.09 & 45.12 & 5.26 \\
\hline
\end{tabular}

Note: $\mathrm{POD}=$ Post-operative day; $\mathrm{SD}=$ Standard deviation

undergoing cardiac surgery. Recruitment of samples to this study was very successful, as only two patients did not accept to participate. All patients who accepted to be a part of this study extended their cooperation to complete the study successfully. Limitations of this study are that we could not randomize the patients and include larger sample size due to lack of resources. In spite of all these limitations, study results have provided a strong foundation for future research work in the arena of yoga in the patients undergoing cardiac surgery.

\subsection{Implications for practice}

This study proved that pranayama significantly benefits patients undergoing cardiac surgery in improving postoperative outcomes. As the results suggests that pranayama is decreasing anxiety among patients undergoing cardiac surgery, it can be considered as one of the non-pharmacologic intervention. However, it is difficult to draw conclusion on effect of pranayama until further research develops more evidence to support this intervention for clinical practice. As there is an increasing awareness of yoga worldwide, there is a need for highquality randomized controlled trials with larger sample size to prove this results. Future trials also should focus on estimation of relevant biomarkers such as endorphins, as the scientific mechanism is not yet understood clearly. Qualitative studies also can be conducted to know about the patient's experiences in performing pranayama and yoga.

\section{Conclusion}

Considering that pain and anxiety are usual after cardiac surgery,

Table 3

Repeated measures ANOVA on anxiety for experimental and control group $\mathrm{N}=48$.

\begin{tabular}{|c|c|c|c|c|c|c|c|c|}
\hline \multirow[t]{2}{*}{ Outcome } & \multirow{2}{*}{$\frac{\text { Before Surgery }}{\text { Mean } \pm \text { SD }}$} & \multirow{2}{*}{$\frac{2^{\text {nd }} P O D}{\text { Mean } \pm S D}$} & \multirow{2}{*}{$\begin{array}{l}5^{\text {th }} \mathrm{POD} \\
\text { Mean } \pm S D\end{array}$} & \multicolumn{2}{|c|}{ Time effect } & \multicolumn{2}{|c|}{ Group effect } & \multirow[t]{2}{*}{$\eta_{p}^{2}$} \\
\hline & & & & $F$ & $p$ & $F$ & $p$ & \\
\hline $\begin{array}{c}\text { Experimental } \\
\text { Group }\end{array}$ & $55.08 \pm 4.45$ & $49.20 \pm 5.67$ & $39.25 \pm 3.09$ & 82.02 & .001 & 9.62 & .001 & .641 \\
\hline $\begin{array}{l}\text { Control } \\
\text { Group }\end{array}$ & $55.54 \pm 6.71$ & $49.66 \pm 6.21$ & $45.12 \pm 5.26$ & & & & & \\
\hline
\end{tabular}

$\mathrm{SD}=$ Standard deviation; POD: Post-operative day; $\eta_{p}^{2}=$ partial eta squared (effect size). 
Table 4

Repeated measures ANOVA on pain for experimental and control group $\mathrm{N}=48$.

\begin{tabular}{|c|c|c|c|c|c|c|c|}
\hline \multirow[t]{2}{*}{ Outcome } & \multirow{2}{*}{$\begin{array}{l}\text { Pre-intervention } \\
\text { Mean } \pm \text { SD }\end{array}$} & \multirow{2}{*}{$\begin{array}{l}\text { Post-intervention } \\
\text { Mean } \pm \text { SD }\end{array}$} & \multicolumn{2}{|c|}{ Time effect } & \multicolumn{2}{|c|}{ Group effect } & \multirow{2}{*}{$\eta_{p}^{2}$} \\
\hline & & & $F$ & $p$ & $F$ & $p$ & \\
\hline \multicolumn{8}{|l|}{ Anxiety } \\
\hline Experimental Group & $49.20 \pm 5.67$ & $39.25 \pm 3.09$ & 215.9 & .001 & 36.0 & .001 & .440 \\
\hline Control Group & $53.58 \pm 3.09$ & $45.12 \pm 1.56$ & & & & & \\
\hline \multicolumn{8}{|l|}{ Pain - 3rd POD } \\
\hline Experimental Group & $50.83 \pm 6.53$ & $48.75 \pm 5.36$ & 12.10 & .001 & 6.48 & .014 & .123 \\
\hline Control Group & $55.42 \pm 7.21$ & $53.33 \pm 7.02$ & & & & & \\
\hline \multicolumn{8}{|l|}{ Pain - 4th POD } \\
\hline Experimental Group & $47.92 \pm 4.14$ & $42.92 \pm 5.50$ & 32.66 & .001 & 0.54 & .466 & .012 \\
\hline Control Group & $49.17 \pm 4.08$ & $43.33 \pm 6.37$ & & & & & \\
\hline \multicolumn{8}{|l|}{ Pain - 5th POD } \\
\hline Experimental Group & $42.50 \pm 5.31$ & $30.83 \pm 5.83$ & 106.2 & .001 & 0.02 & .865 & .001 \\
\hline Control Group & $42.92 \pm 6.24$ & $30.88 \pm 5.86$ & & & & & \\
\hline
\end{tabular}

$\mathrm{SD}=$ Standard deviation; POD: Post-operative day; $\eta_{p}^{2}=$ partial eta squared (effect size).

Assessed for the eligibility ( $n=57)$.

pranayama can be a useful intervention for reduction of pain and anxiety among patients undergoing heart surgery to promote the speedy recovery. Our study results support the use of non-pharmacological interventions for the relief of pain and anxiety in postoperative nursing care. Additional research is also warranted to discover the benefits of alternative nostril breathing exercise (Pranayama) in the long term among patients with cardiovascular conditions.

\section{Conflicts of interest}

There are no conflicts of interest to declare.

\section{Acknowledgement}

We express our sincere thanks to all patients who participated and extended their support in this research study.

\section{Appendix A. Supplementary data}

Supplementary data to this article can be found online at https:// doi.org/10.1016/j.cegh.2019.01.009.

\section{Funding}

The authors have received no funding.

\section{References}

1. Sharif F, Shoul A, Janati M, Kojuri J, Zare N. The effect of cardiac rehabilitation on anxiety and depression in patients undergoing cardiac bypass graft surgery in Iran. BMC Cardiovasc Disord. 2012;12:40. https://doi.org/10.1186/1471-2261-12-40.

2. Ramesh C, Nayak BS, Pai VB, George A, George LS, Devi ES. Pre-operative anxiety in patients undergoing coronary artery bypass graft surgery - a cross-sectional study. Int J Africa Nurs Sci. 2017;7. https://doi.org/10.1016/j.ijans.2017.06.003.

3. Guo P, East L, Arthur A. A preoperative education intervention to reduce anxiety and improve recovery among Chinese cardiac patients: a randomized controlled trial. Int J Nurs Stud. 2012;49:129-137. https://doi.org/10.1016/j.ijnurstu.2011.08.008.

4. Bauer BA, Cutshall SM, Wentworth LJ, et al. Effect of massage therapy on pain, anxiety, and tension after cardiac surgery: a randomized study. Complement Ther Clin Pract. 2010;16:70-75. https://doi.org/10.1016/j.ctcp.2009.06.012.

5. Sharma M, Haider T. Yoga as an alternative and complementary treatment for hypertensive patients: a systematic review. J Evid Based Complementary Altern Med. 2012;17:199-205. https://doi.org/10.1177/2156587212452144.

6. Lakkireddy D, Atkins D, Pillarisetti J, et al. Effect of yoga on arrhythmia burden, anxiety, depression, and quality of life in paroxysmal atrial fibrillation: the YOGA my heart study. J Am Coll Cardiol. 2013;61:1177-1182. https://doi.org/10.1016/j.jacc. 2012.11.060.

7. McKay JAA, McCulloch CL, Querido JS, Foster GE, Koehle MS, Sheel AW. The effect of consistent practice of yogic breathing exercises on the human cardiorespiratory system. Respir Physiol Neurobiol. 2016;233:41-51. https://doi.org/10.1016/j.resp. 2016.07.005.

8. Turankar AV, Jain S, Patel SB, et al. Effects of slow breathing exercise on cardiovascular functions, pulmonary functions \& galvanic skin resistance in healthy human volunteers - a pilot study. Indian J Med Res. 2013;137:916-921.

9. Yadav A, Singh S, Singh KP. Role of Pranayama breathing exercises in rehabilitation of coronary artery disease patients- A pilot study. Indian J Tradit Knowl. 2009;8:455-458.

10. Pramanik T, Sharma HO, Mishra S, Mishra A, Prajapati R, Singh S. Immediate effect of slow pace Bhastrika pranayama on blood pressure and heart rate. J Alternative Compl Med. 2009;15:293-295. https://doi.org/10.1089/acm.2008.0440.

11. Raghuram N, Parachuri VR, Swarnagowri MV, et al. Yoga based cardiac rehabilitation after coronary artery bypass surgery: one-year results on LVEF, lipid profile and psychological states - a randomized controlled study. Indian Heart $J$. 2014;66:490-502. https://doi.org/10.1016/j.ihj.2014.08.007.

12. Chu P, Gotink R a, Yeh GY, Goldie SJ, Hunink MM. The effectiveness of yoga in modifying risk factors for cardiovascular disease and metabolic syndrome: a systematic review and meta-analysis of randomized controlled trials. Eur J Prev Cardiol. 2014;111(1):2047487314562741https://doi.org/10.1177/2047487314562741.

13. Cramer H, Lauche R, Haller H, Steckhan N, Michalsen A, Dobos G. Effects of yoga on cardiovascular disease risk factors: a systematic review and meta-analysis. Int $J$ Cardiol. 2014;173(2):170-183. https://doi.org/10.1016/j.ijcard.2014.02.017.

14. Amaravathi E, Ramarao NH, Raghuram N, Pradhan B. Yoga-based postoperative cardiac rehabilitation program for improving quality of life and stress levels: fifthyear follow-up through a randomized controlled trial. Int J Yoga. 2018;11(1):44-52. https://doi.org/10.4103/ijoy.IJOY_57_16.

15. McGonigle S, Styra R, StJacques A, Bailey B, Dimas M. Abstract P028: MY program modified yoga after cardiac surgery reduces stress, pain and anxiety. Circulation. 2017;135(suppl 1) AP028 LP-AP028 http://circ.ahajournals.org/content/135/ Suppl_1/AP028.abstract.

16. World Medical Association. World Medical Association Declaration of Helsinki: ethical principles for medical research involving human subjects. $J$ Am Med Assoc. 2017;310(20):2191-2194http://doi.org/10.1001/jama.2013.281053.

17. Hawker GA, Mian S, Kendzerska T, French M. Measures of adult pain: visual analog scale for pain (VAS pain), numeric rating scale for pain (NRS pain), McGill pain questionnaire (MPQ), short-form McGill pain questionnaire (SF-MPQ), chronic pain grade scale (CPGS), short form-36 Bodily pain scale (SF). Arthritis Care Res. 2011;63:240-252. https://doi.org/10.1002/acr.20543.

18. Aysel G, Bilgi G, Aygen E. Yoga after coronary artery bypass graft surgery: its effect on anxiety and self-care agency. Health Med. 2013;7:211.

19. Dabhade AM, Pawar BH, Ghunage MS, Ghunage VM. Effect of pranayama (breathing exercise) on arrhythmias in the human heart. Explore J Sci Heal. 2012;8:12-15. https://doi.org/10.1016/j.explore.2011.10.004.

20. Rocha KKF, Ribeiro AM, Rocha KCF, et al. Improvement in physiological and psychological parameters after 6 months of yoga practice. Conscious Cognit. 2012;21:843-850https://doi.org/10.1016/j.concog.2012.01.014.

21. Field T. Yoga research review. Complement Ther Clin Pract. 2016;24:145-161. https://doi.org/10.1016/j.ctcp.2016.06.005. 